\title{
A novel insight of sentinel lymph node concept based on 1-3 positive nodes in patients with pT1-2 gastric cancer
}

\author{
Baojun Huang ${ }^{1}$, Zhenning Wang ${ }^{1}$, Zhe Sun ${ }^{1}$, Bo Zhao ${ }^{2}$, Huimian Xu ${ }^{1 *}$
}

\begin{abstract}
Background: Sentinel node (SN) biopsy has been practiced in gastric cancer in recent years, and many studies focused on the distribution of solitary lymph node metastasis (SLM) to assess the pattern of SN. In fact, there is usually more than one SN existing in gastric cancer. The distribution of SNs needs to be further re-evaluated.

Methods: A total of 289 patients in pT1-2 stage with 1-3 positive nodes confined to same compartment were included in this study with informed consents. The primary lesion was solitary $(\leq 5.0 \mathrm{~cm}$ in diameter) and D2 or D3 lymph node dissection had been performed. The location of metastatic lymph nodes was analyzed retrospectively.

Results: Most positive nodes occurred in N1 compartment, with frequency of $79.6 \%$ to $85.7 \%$ based on site of tumor. In the lower third of stomach, no. 6 was the most common metastatic site and no. 3 was the second; the order was reversed for SLM. With increasing depth of tumor invasion, a progressively augmented nodal involvement was shown. Nearly a half appeared transverse metastasis when the tumor located at the lesser or greater curvature. Among skip metastasis, no. 7, 8a, 9 and 11p were the most common metastatic sites and the prognosis was as similar as that of patients with $\mathrm{N} 1$ involved only.

Conclusions: The 1-3 positive nodes in the same compartment should be possible SNs, and most of which are restricted in N1 in pT1-2 gastric cancer. Transversal and 2 stations lymph node metastasis are common.
\end{abstract}

\section{Background}

Although the incidence of gastric cancer is declining, it remains the second leading cause of cancer related mortality worldwide [1-3]. Lymph node status is one of the crucial important prognostic factors, and gastrectomy with D2 or D3 lymphadenectomy is still considered as the only treatment offering hope of a cure for gastric cancer. However, the incidence of nodal involvement in gastric cancer is significantly different according to the depth of tumor invasion (T1-T4) [4-7]. Uniform application of this highly invasive procedure would increase morbidity and reduce the quality of life after surgery, especially for those with early stage cancers. However, the optimal strategy of lymphadenectomy for gastric cancer is still under debate.

\footnotetext{
* Correspondence: xuhuimian@126.com

${ }^{1}$ Department of Surgical Oncology, the First Hospital of China Medical University, Shenyang, 110001, PR China

Full list of author information is available at the end of the article
}

Sentinel node (SN) is defined as the first lymph node which receives lymphatic drainage from the primary tumor. Sentinel node biopsy (SNB) has been widely applicated as an alternate treatment to maintain the quality of life for cT1-2 gastric cancer patients in recent years. However, this technique is still unsatisfactory for clinical application due to its high heterogeneity in sensitivity, specificity and accuracy (from $61.1 \%$ to $100 \%$ ) [8-12]. There are several potential explanations for these results: 1) different examining methods which need to be standardized; 2) limited sample size of participants and sentinel nodes examined; 3) patients in late stage included occasionally; 4) multidirectional and complicated lymphatic flow from stomach. Resolving the above problems could improve the accuracy of SNB practice in gastric cancer.

Up to now, many studies have investigated the localization and distribution of solitary lymph node metastasis (SLM) in order to provide some useful information for SN concept in gastric cancer, which may offset the 
insufficiency of study sample size in SNB studies [13-16]. However, the lymphatic drainage of the stomach is considerably more complex than that of ectodermal organs like breast and skin. The multidirectional and complicated lymphatic flow from stomach results in more than one node, which should be considered as $\mathrm{SN}$ for gastric cancer. Furthermore, many investigations have showed that the number of SN per patient is 1-12 with an average of 3 [8,17-19]. Consequently, using SLM to assess the distribution of SNs in gastric cancer may leave out some important information, thus it might be more appropriate to practice the SN concept based on more than one metastatic lymph node.

In the light of these considerations, the aim of the present study was to assess the distribution of 1-3 positive nodes in pT1-2 gastric cancer patients. This would provide some new information for the concept of SNs in gastric cancer, especially in early stage of tumor.

\section{Methods}

A retrospective analysis of clinicopathologic data for gastric cancer patients from a prospectively collected gastric cancer database from February 1980 to November 2006, at the Department of Surgical Oncology, First Affiliated Hospital, China Medical University, was performed. The criteria for inclusion in this study were as follows: (1) primary lesion was solitary $(\leq 5.0 \mathrm{~cm}$ in diameter) and limited to one part of the stomach; (2) patients were in pT1-2 stage according to the $6^{\text {th }}$ UICC/ TNM classification; (3) D2 or D3 lymph node dissection had been performed; (4) patients had 1-3 metastatic lymph nodes which restricted to the same compartment according to JCGC; (5) the number of examined lymph node was more than 10; (6) all the patients clinically staged as no macroscopic serosal invasion (cT1-2) and node negative ( $\mathrm{cNO}$ ) before or during surgery. A total of 297 patients with gastric cancer were included. At the end of follow-up in December 2008, 4 patients died in the postoperative period and 4 patients were lost, with the follow-up rate of $97.3 \%$. The median and mean follow-up period was 45.0 and 68.8 months (3-342 months), respectively. Overall, 289 patients with gastric cancer were enrolled into this study with their informed consents.

We first retrospectively investigated the localization and distribution of 1-3 positive nodes confined to the same compartment according to Japanese Classification of Gastric Carcinoma (JCGC), which were regarded as possible sentinel lymph nodes, and then compared those with solitary lymph node metastasis (SLM). The differences were identified between the two groups. Then the clinical and pathological features were analyzed for patients with transversal and two stations metastasis.
The study protocol was approved by the Ethics Committee of China Medical University.

\section{Statistical analysis}

Data were analyzed using the SPSS statistical software (SPSS, Chicago, IL). The difference of nodes distribution between SLM and 1-3 positive nodes was tested by the chi-square test or Fisher's exact probability test. The univariate analysis was used by the chi-square test for categorical variables and unpaired t-test for continuous variables between groups. The multivariate analysis was used binary logistic regression. The survival analysis was used by Kaplan-Meier estimation and log-rank test. $P<$ 0.05 was considered to be statistically significant.

\section{Results}

\section{Clinicopathologic features}

Among the patients, the age (mean \pm SD) was $58.9 \pm$ 10.4 years (ranging from 29 to 84 years). More men than women (224 men versus 65 women) participated in the study. Carcinomas were located in the lower third of stomach (L) in 207 patients, middle third (M) in 28 patients and upper third (U) in 54 patients. Tumors were located in the lesser curvature in 131 patients and in the greater curvature in 63 patients, respectively. Distal-gastrectomy was executed in 223 patients, proximalgastrectomy in 47 patients and total-gastrectomy in 19 patients. Lymphadenectomy was executed based on the Japanese Classification of Gastric Carcinoma (JCGC) [20]. D2 lymph node dissection was performed in 212 patients, and D3 in 77 patients. The number of lymph node retrieved ranged from 10 to 55 with an average of $20.9 \pm 9.9$ (mean \pm SD). Among them 10-14 retrieved nodes were in 97 patients and $\geq 15$ retrieved nodes in 192 patients, respectively.

According to the depth of tumor invasion, pT1 cancer was diagnosed in 28 patients $(9.7 \%)$, with protruded type (I, IIa) in 3 patients (10.7\%) and depressed type (IIc, III) in 25 patients (89.3\%), respectively. The pT2a cancer was diagnosed in 92 patients $(31.8 \%)$, and pT2b cancer in 169 patients (58.5\%), with Borrmann I/II in 54 patients (20.7\%) and Borrmann III/IV in 207 patients (79.3\%) based on macroscopic type. The tumor diameter ranged from 0.5 to $5.0 \mathrm{~cm}$ with an average of $3.9 \pm 1.1$ $\mathrm{cm}$ (mean $\pm \mathrm{SD})$. Well and/or moderately differentiated tumor was found in 129 patients (44.6\%), and poorly differentiated tumor in 160 patients (55.4\%) according to the histology. Diffuse-type was found in 170 patients (58.8\%), intestinal-type in 111 patients (38.4\%), and mixed-type carcinoma in 8 patients $(2.8 \%)$ based on Lauren classification. SLM was found in 173 patients, 2 positive nodes in 75 patients, and 3 positive nodes in 41 patients, respectively. The metastatic lymph node restricted to one station was in 235 patients and two 
stations in the same compartment in 54 patients. The N1 compartment nodes were involved in 237 patients and N2 (skip metastasis) in 52 patients in light of JCGC.

\section{Location and distribution of 1-3 metastatic lymph nodes in gastric cancer}

Among 207 patients with lower-third tumor, 170 patients $(82.1 \%)$ had lymph node metastasis in the perigastric nodes (N1) close to the primary tumor and no. 6/3 was the most common site. The other 37 patients (17.9\%) were found in $\mathrm{N} 2$ without N1 involvement. Of 28 patients with middle-third tumor, 24 patients (85.7\%) had lymph node metastasis in $\mathrm{N} 1$ and skip metastasis was found in 4 patients $(14.3 \%)$. In 54 patients with upper-third tumor, 43 patients (79.6\%) metastasized in $\mathrm{N} 1$, and skip metastasis occurred in 11 patients $(20.4 \%)$. In $\mathrm{N} 2$ compartment, no. 11p and 12a were also involved apart from no. 7, 8a and 9. The detailed frequency of different station involved in $\mathrm{N} 1$ and $\mathrm{N} 2$ was displayed in table 1 .

\section{Difference of location and distribution between SLM and 1-3 positive nodes in gastric cancer}

With respect to the tumor in lower third of stomach, there was no significant difference in frequency and distribution of skip metastasis between SLM and 1-3 positive nodes, and the no. 7, 8a and 9 were the most common target stations. In N1 compartment, the frequency of no. 5 and no. 6 involved in patients with 1-3 positive nodes was higher than that in patients with

Table 1 Localization and distribution of 1-3 positive lymph nodes in 289 patients with gastric cancer

\begin{tabular}{|c|c|c|c|}
\hline \multirow[b]{2}{*}{ station } & \multicolumn{3}{|c|}{ Tumor Location } \\
\hline & L (\%) & M (\%) & U (\%) \\
\hline no.1 & $8(3.9)$ & $3(10.7)$ & $24(44.4)$ \\
\hline no.2 & - & $1(3.6)$ & $9(16.7)$ \\
\hline no.3 & $62(30.0)$ & $13(46.4)$ & $15(27.8)$ \\
\hline no.4d & $37(17.9)$ & $6(21.4)$ & $4(7.4)$ \\
\hline no.5 & $29(14.0)$ & $5(17.9)$ & 0 \\
\hline no.6 & $75(36.2)$ & $2(7.1)$ & 0 \\
\hline no.7 & $12(5.8)$ & $3(10.7)$ & $6(11.1)$ \\
\hline no.8a & $13(6.3)$ & $1(3.6)$ & $4(7.4)$ \\
\hline no.9 & $3(1.4)$ & 0 & $2(3.7)$ \\
\hline no.10 & 0 & - & $1(1.9)$ \\
\hline no.11p & $3(1.4)$ & 0 & $2(3.7)$ \\
\hline no. $12 \mathrm{a}$ & 0 & $1(3.6)$ & 0 \\
\hline \multicolumn{4}{|c|}{ compartment (JCGC) } \\
\hline N1 & $170(82.1)$ & $24(85.7)$ & $43(79.6)$ \\
\hline $\mathrm{N} 2$ & $37(17.9)$ & $4(14.3)$ & $11(20.4)$ \\
\hline \multicolumn{4}{|l|}{ number of station } \\
\hline 1 & $172(83.1)$ & $21(75.0)$ & $41(75.9)$ \\
\hline 2 & 35 (16.9) & $7(25.0)$ & $13(24.1)$ \\
\hline
\end{tabular}

SLM $(p<0.05)$. Furthermore, in patients with $1-3$ positive nodes no. 6 was the most common metastatic site, and no. 3 was the second, this was reversed to that in patients with SLM. As to the tumor in middle and upper third of stomach, the location and distribution of metastatic node in $\mathrm{N} 1$ and $\mathrm{N} 2$ compartment was similar in patients with SLM and 1-3 positive nodes, there was no significant difference $(p>0.05)$ (Table 2).

Pattern of distribution of 1-3 metastatic lymph nodes in gastric cancer according to the depth of tumor invasion Among the tumors of different depth of invasion ( $\mathrm{T} 1$, $\mathrm{T} 2 \mathrm{a}$ and $\mathrm{T} 2 \mathrm{~b}$ ), the pattern of lymph node metastasis in $\mathrm{N} 1$ and N2 compartment was similar. With an increase of $\mathrm{T}$ parameter, a progressively augmented nodal involvement was showed in some stations. In lower third of stomach, no. 6 was the most common station, from $25 \%$ in $\mathrm{T} 1$ to $39 \%$ in $\mathrm{T} 2 \mathrm{a}$, and to $36.4 \%$ in T2b tumors. The no. 3 was the second common, from $25 \%$ in $\mathrm{T} 1$ to $26 \%$ in $\mathrm{T} 2 \mathrm{a}$, and to $33.6 \%$ in T2b tumors. The no. 1 and no. 9 was not involved in T1 tumors, but was involved in T2a and T2b tumors. In middle third of stomach, no. 3 was the most common station, $40 \%$ in $\mathrm{T} 1,37.5 \%$ in $\mathrm{T} 2 \mathrm{a}$ and $53.3 \%$ in T2b tumors. In upper third of stomach, no. 1 and no. 3 was the common metastatic site, and the frequency of N2 involved was much higher in $\mathrm{T} 2 \mathrm{~b}$ than that in T2a and T1 tumors. The skip metastasis often occurred in no. 7, 8a, 9, 10, and $11 \mathrm{p}$ in T2b tumors, but it seldom occurred in $\mathrm{T} 2 \mathrm{a}$ and $\mathrm{T} 1$ tumors (Table 3).

\section{Transversal and two stations metastasis with 1-3 metastatic lymph nodes in gastric cancer}

A total of $32(50.8 \%)$ in the 63 patients with tumor in the greater curvature side had transversal metastasis. There were 5 cases metastasis in no. 1 station and 4 cases in no. 3 station among 13 patients in the upper third of stomach, and 2 cases in no. 3 and 1 case in no. 5 among 5 patients in the middle, and 14 cases in no. 3 and 6 cases in no. 5 among 45 patients in the lower third of stomach. $54(41.2 \%)$ in the 131 patients with tumor in the lesser curvature side had transversal metastasis. There were 5 cases in no. 2 among 22 patients in the upper third of stomach, and just 1 case in no. 6 among 11 patients in the middle, and 15 cases in no. 4 and 33 cases in no. 6 among 98 patients in the lower third of stomach.

With respect to patients with two stations involved, in 34 tumors located in the lower third of stomach, 11 (32.4\%) patients metastasized simultaneously in no. 5/6. No. 3/4 and no. 3/6 were both involved in $6(17.6 \%)$ and $7(20.6 \%)$ patients, respectively. The rest patients metastasized in no. $4 / 5$, no. $4 / 6$ and no. $3 / 5$. Of note, 2 cases metastasized in no. 7/8a without N1 involvement. 
Table 2 Difference between distribution of SLM and 1-3 positive nodes in gastric cancer

\begin{tabular}{|c|c|c|c|c|c|c|c|c|c|c|c|c|}
\hline \multirow[b]{2}{*}{ station } & \multicolumn{3}{|c|}{ Lower third (\%) } & \multirow[b]{2}{*}{$p$} & \multicolumn{3}{|c|}{ Middle third (\%) } & \multirow[b]{2}{*}{$p$} & \multicolumn{3}{|c|}{ Upper third (\%) } & \multirow[b]{2}{*}{$p$} \\
\hline & SLM & $1-3$ & $x$ & & SLM & $1-3$ & $x$ & & SLM & $1-3$ & $x$ & \\
\hline no.1 & 6.2 & 3.9 & 0.96 & 0.328 & 5.9 & 10.7 & 0.31 & 0.581 & 33.3 & 44.4 & 0.92 & 0.337 \\
\hline no. 2 & - & - & - & - & 5.9 & 3.6 & 0.13 & 0.715 & 18.5 & 16.7 & 0.04 & 0.835 \\
\hline no.3 & 27.9 & 30 & 0.16 & 0.688 & 41.2 & 46.4 & 0.12 & 0.731 & 29.6 & 27.8 & 0.03 & 0.862 \\
\hline no.4d & 15.5 & 17.9 & 0.32 & 0.573 & 17.6 & 21.4 & 0.10 & 0.758 & 7.4 & 7.4 & 0.00 & 1.000 \\
\hline no.5 & 6.9 & 14 & 3.92 & $0.048^{*}$ & 11.8 & 17.9 & 0.30 & 0.585 & 0 & 0.0 & - & - \\
\hline no.6 & 25.6 & 36.2 & 4.13 & $0.042^{*}$ & 0 & 7.1 & 1.27 & 0.260 & 0 & 0.0 & - & - \\
\hline no.7 & 7.8 & 5.8 & 0.50 & 0.481 & 11.8 & 10.7 & 0.01 & 0.913 & 7.4 & 11.1 & 0.28 & 0.598 \\
\hline no.8a & 6.9 & 6.3 & 0.06 & 0.802 & 5.9 & 3.6 & 0.13 & 0.715 & 3.7 & 7.4 & 0.43 & 0.514 \\
\hline no.9 & 2.3 & 1.4 & 0.35 & 0.555 & 0 & 0.0 & - & - & 0 & 3.7 & 1.03 & 0.311 \\
\hline \multicolumn{13}{|l|}{ compartment } \\
\hline N1 & 76.0 & 82.1 & 1.87 & 0.172 & 82.4 & 85.7 & 0.09 & 0.763 & 88.9 & 79.6 & 1.91 & 0.167 \\
\hline N2 & 24.0 & 17.9 & & & 17.6 & 14.3 & & & 11.1 & 20.4 & & \\
\hline
\end{tabular}

note: SLM refers to solitary lymph node metastasis; 1-3 refers to 1-3 positive nodes.

* indicates the difference is significant.

Table 3 Incidence of 1-3 positive lymph nodes in gastric cancer patients according to the depth of tumor invasion (\%)

\begin{tabular}{|c|c|c|c|c|c|c|c|c|c|}
\hline \multirow[b]{2}{*}{ station } & \multicolumn{3}{|c|}{ Lower third } & \multicolumn{3}{|c|}{ Middle third } & \multicolumn{3}{|c|}{ Upper third } \\
\hline & T1 & T2a & $\mathrm{T} 2 \mathrm{~b}$ & T1 & T2a & $\mathrm{T} 2 \mathrm{~b}$ & T1 & $\mathrm{T} 2 \mathrm{a}$ & $\mathrm{T} 2 \mathrm{~b}$ \\
\hline no.1 & 0 & $\begin{array}{c}2 \\
(2.6)\end{array}$ & $\begin{array}{c}6 \\
(5.5)\end{array}$ & $\begin{array}{c}3 \\
(60.0)\end{array}$ & 0 & 0 & $\begin{array}{c}1 \\
(33.3)\end{array}$ & $\begin{array}{c}5 \\
(71.4)\end{array}$ & $\begin{array}{c}18 \\
(40.9)\end{array}$ \\
\hline no.2 & - & - & - & - & $\begin{array}{c}1 \\
(12.5)\end{array}$ & 0 & 0 & $\begin{array}{c}1 \\
(14.3)\end{array}$ & $\begin{array}{c}8 \\
(18.2)\end{array}$ \\
\hline no.3 & $\begin{array}{c}5 \\
(25.0)\end{array}$ & $\begin{array}{c}20 \\
(26.0)\end{array}$ & $\begin{array}{c}37 \\
(33.6)\end{array}$ & $\begin{array}{c}2 \\
(40.0)\end{array}$ & $\begin{array}{c}3 \\
(37.5)\end{array}$ & $\begin{array}{c}8 \\
(53.3)\end{array}$ & $\begin{array}{c}1 \\
(33.3)\end{array}$ & $\begin{array}{c}2 \\
(28.6)\end{array}$ & $\begin{array}{c}12 \\
(27.3)\end{array}$ \\
\hline no.4d & $\begin{array}{c}6 \\
(30.0)\end{array}$ & $\begin{array}{c}15 \\
(19.5)\end{array}$ & $\begin{array}{c}16 \\
(14.5)\end{array}$ & 0 & $\begin{array}{c}1 \\
(12.5)\end{array}$ & $\begin{array}{c}5 \\
(33.3)\end{array}$ & 0 & 0 & $\begin{array}{c}4 \\
(9.1)\end{array}$ \\
\hline no.5 & $\begin{array}{c}2 \\
(10.0)\end{array}$ & $\begin{array}{c}12 \\
(15.6)\end{array}$ & $\begin{array}{c}15 \\
(13.6)\end{array}$ & 0 & $\begin{array}{c}2 \\
(25.0)\end{array}$ & $\begin{array}{c}3 \\
(20.0)\end{array}$ & 0 & 0 & 0 \\
\hline no.6 & $\begin{array}{c}5 \\
(25.0)\end{array}$ & $\begin{array}{c}30 \\
(39.0)\end{array}$ & $\begin{array}{c}40 \\
(36.4)\end{array}$ & 0 & $\begin{array}{c}1 \\
(12.5)\end{array}$ & $\begin{array}{c}1 \\
(6.7)\end{array}$ & 0 & 0 & 0 \\
\hline no.7 & $\begin{array}{c}2 \\
(10.0)\end{array}$ & $\begin{array}{c}5 \\
(6.5)\end{array}$ & $\begin{array}{c}5 \\
(4.5)\end{array}$ & 0 & $\begin{array}{c}2 \\
(25.0)\end{array}$ & $\begin{array}{c}1 \\
(6.7)\end{array}$ & $\begin{array}{c}1 \\
(33.3)\end{array}$ & 0 & $\begin{array}{c}6 \\
(13.6)\end{array}$ \\
\hline no.8a & $\begin{array}{c}1 \\
(5.0)\end{array}$ & $\begin{array}{c}3 \\
(3.9)\end{array}$ & $\begin{array}{c}9 \\
(8.2)\end{array}$ & $\begin{array}{c}1 \\
(20.0)\end{array}$ & 0 & 0 & - & 0 & $\begin{array}{c}3 \\
(6.8)\end{array}$ \\
\hline no.9 & 0 & $\begin{array}{c}2 \\
(2.6)\end{array}$ & $\begin{array}{c}1 \\
(0.9)\end{array}$ & 0 & 0 & 0 & - & - & $\begin{array}{c}2 \\
(4.5)\end{array}$ \\
\hline no.10 & - & - & 0 & - & - & - & - & - & $\begin{array}{c}1 \\
(2.3)\end{array}$ \\
\hline no.11p & - & $\begin{array}{c}1 \\
(1.3)\end{array}$ & $\begin{array}{c}2 \\
(1.8)\end{array}$ & - & 0 & 0 & - & 0 & $\begin{array}{c}2 \\
(4.5)\end{array}$ \\
\hline no.12a & 0 & 0 & 0 & 0 & $\begin{array}{c}1 \\
(12.5)\end{array}$ & 0 & - & 0 & 0 \\
\hline \multicolumn{10}{|c|}{ compartment (JCGC) } \\
\hline N1 & $\begin{array}{c}18 \\
(90.0)\end{array}$ & $\begin{array}{c}64 \\
(83.1)\end{array}$ & $\begin{array}{c}88 \\
(80.0)\end{array}$ & $\begin{array}{c}4 \\
(80.0)\end{array}$ & $\begin{array}{c}6 \\
(75.0)\end{array}$ & $\begin{array}{c}14 \\
(93.3)\end{array}$ & $\begin{array}{c}2 \\
(66.7)\end{array}$ & $\begin{array}{c}7 \\
(100.0)\end{array}$ & $\begin{array}{c}34 \\
(77.3)\end{array}$ \\
\hline N2 & $\begin{array}{c}2 \\
(10.0)\end{array}$ & $\begin{array}{c}13 \\
(16.9)\end{array}$ & $\begin{array}{c}22 \\
(20.0)\end{array}$ & $\begin{array}{c}1 \\
(20.0)\end{array}$ & $\begin{array}{c}2 \\
(25.0)\end{array}$ & $\begin{array}{c}1 \\
(6.7)\end{array}$ & $\begin{array}{c}1 \\
(33.3)\end{array}$ & - & $\begin{array}{c}10 \\
(22.7)\end{array}$ \\
\hline \multicolumn{10}{|l|}{ number of station } \\
\hline 1 & $\begin{array}{c}19 \\
(95.0)\end{array}$ & $\begin{array}{c}65 \\
(84.4)\end{array}$ & $\begin{array}{c}89 \\
(80.9)\end{array}$ & $\begin{array}{c}4 \\
(80.0)\end{array}$ & $\begin{array}{c}5 \\
(62.5)\end{array}$ & $\begin{array}{c}12 \\
(80.0)\end{array}$ & $\begin{array}{c}3 \\
(100.0)\end{array}$ & $\begin{array}{c}6 \\
(85.7)\end{array}$ & $\begin{array}{c}32 \\
(72.7)\end{array}$ \\
\hline 2 & $\begin{array}{c}1 \\
(5.0)\end{array}$ & $\begin{array}{c}12 \\
(15.6)\end{array}$ & $\begin{array}{c}21 \\
(19.1)\end{array}$ & $\begin{array}{c}1 \\
(20.0)\end{array}$ & $\begin{array}{c}3 \\
(37.5)\end{array}$ & $\begin{array}{c}3 \\
(20.0)\end{array}$ & - & $\begin{array}{c}1 \\
(14.3)\end{array}$ & $\begin{array}{c}12 \\
(27.3)\end{array}$ \\
\hline
\end{tabular}


One was proved as sm (pT1) and the other as mp (pT2a) pathologically. Among 7 patients in the middle, no. 3/4, no. $5 / 6$ and no. $1 / 3$ were common metastatic stations. In 13 patients located in the upper third of stomach, no. 1/3 were the most common target sites, metastasized in 4 (30.8\%) patients. It was worth noting that 4 cases with two stations involved appeared in N2 compartment (no. 8/9, no. 9/11, no. 8/10 and no. 7/11 stations involved, respectively), which amounted to $1.1 \%$ in 44 patients of upper third of stomach with 1-3 positive nodes, and who were all proved as ss (pT2b) pathologically.

In order to find some associated factors with transversal and 2 stations node involved, the correlation between clinicopathological features and them was analyzed. However, there was no significant association between them (detailed in table 4). The most possible reason for the high frequency of transversal and 2 stations lymph node metastasis might be the multidirectional and complicated lymphatic flow from stomach.

Influenced factors and survival analysis of skip metastasis A total of 52 patients occurred skip metastasis. In order to find factors influencing skip metastasis, the correlation was assessed between skip metastasis and clinicopathologic factors which includes gender, age, tumor location, tumor size, macroscopic type, differentiation, Lauren classification, depth of tumor invasion and vessel involvement. As a result, no clinicopathologic factor was found to be associated with skip metastasis using univariate and multivariate analysis (data not shown).

A little decrease of survival rate was showed in patients with skip metastasis. The 5-year, 10-year survival rate in patients with and without skip metastasis was $55.3 \%, 49.7 \%$ and $68.2 \%, 61.3 \%$, respectively. However, no significant difference was detected between the two groups $\left(\mathrm{x}^{2}=0.168, p=0.1951\right)$ using log rank test (figure 1), which meant the prognosis of patients with skip metastasis (N2) was as similar as that of patients with N1 involvement.

\section{Discussion}

In order to accurately assess the sentinel lymph node distribution in gastric cancer, the criteria for inclusion in this study were defined very strictly. First, the primary tumor of $5.0 \mathrm{~cm}$ or less in diameter ensured that the lesion occupied only one part of the stomach, which could diminish the interactive effect from location overlap. Ichikura $\mathrm{T}$ et al. assessed the applicability of the sentinel node concept to gastric carcinoma based on 119 patients with a primary tumor $\leq 5.0 \mathrm{~cm}$ in diameter [21]. Yasuda $\mathrm{K}$ et al. defined a tumor measuring $\geq 5.0$ $\mathrm{cm}$ as superficially spreading cancer of the stomach [22]. These literatures also support that $5.0 \mathrm{~cm}$ or less in diameter is suitable for SNs study in gastric cancer.

Table 4 The correlation between clinicopathological factors and transversal and 2 stations lymph node metastasis

\begin{tabular}{|c|c|c|c|c|c|c|c|c|c|}
\hline \multirow[b]{2}{*}{ factors } & & \multicolumn{4}{|c|}{ transversal metastasis } & \multicolumn{4}{|c|}{2 station positive nodes } \\
\hline & & $-(\%)$ & $+(\%)$ & $x^{2}$ & $P$ value & $-(\%)$ & $+(\%)$ & $x^{2}$ & $P$ value \\
\hline \multirow[t]{2}{*}{ sex } & male & $88(58.3)$ & $63(41.7)$ & 1.878 & 0.171 & $182(81.3)$ & $42(18.7)$ & 0.003 & 0.958 \\
\hline & female & $20(46.5)$ & $23(53.5)$ & & & $53(81.5)$ & $12(18.5)$ & & \\
\hline age (year) & mean $\pm s d$ & $58.4 \pm 9.8$ & $58.3 \pm 11.5$ & 0.005 & $0.942 *$ & $58.6 \pm 10.2$ & $59.5 \pm 11.2$ & 0.204 & $0.652^{*}$ \\
\hline tumor size $(\mathrm{cm})$ & mean $\pm s d$ & $3.6 \pm 1.1$ & $3.5 \pm 1.3$ & 0.195 & $0.659^{*}$ & $3.9 \pm 1.2$ & $4.0 \pm 1.0$ & 0.581 & $0.446^{*}$ \\
\hline \multirow{2}{*}{ lymphadenec-tomy } & more than D2 & $27(60.0)$ & $18(40.0)$ & & & $67(87.0)$ & $10(13.0)$ & & \\
\hline & L & $75(52.4)$ & $68(47.6)$ & & & $173(83.6)$ & $34(16.4)$ & & \\
\hline \multirow[t]{2}{*}{ tumor site } & $M$ & $12(75.0)$ & $4(25.0)$ & 3.29 & 0.193 & $21(75.0)$ & $7(25.0)$ & 2.463 & 0.292 \\
\hline & $U$ & $21(60.0)$ & $14(40.0)$ & & & $41(75.9)$ & $13(24.1)$ & & \\
\hline \multirow[t]{2}{*}{ depth of tumor invasion } & $\mathrm{T} 1$ & $14(58.3)$ & $10(41.7)$ & & & $26(92.9)$ & $2(7.1)$ & & \\
\hline & $\mathrm{T} 2 \mathrm{a}$ & $31(49.2)$ & $32(50.8)$ & 1.582 & 0.453 & 76 (82.6) & $16(17.4)$ & 3.318 & 0.19 \\
\hline \multirow[t]{2}{*}{ differentiation } & well/moderately & $47(54.0)$ & $40(46.0)$ & 0.173 & 0.677 & $102(79.1)$ & $27(20.9)$ & 0.773 & 0.379 \\
\hline & poorly & $61(57.0)$ & $46(43.0)$ & & & $133(83.1)$ & $27(16.9)$ & & \\
\hline \multirow[t]{2}{*}{ macroscopic type } & Borr. 1/2 & $22(64.7)$ & $12(35.3)$ & 1.523 & 0.217 & $47(87.0)$ & $7(13.0)$ & 2.068 & 0.15 \\
\hline & Borr. 3/4 & $72(52.9)$ & $64(47.1)$ & & & $162(78.3)$ & $45(21.7)$ & & \\
\hline \multirow[t]{3}{*}{ lauren type } & intestenal & $41(55.4)$ & $33(44.6)$ & & & 85 (76.6) & $26(23.4)$ & & \\
\hline & diffused & $64(56.1)$ & $50(43.9)$ & 0.09 & 0.956 & $142(83.5)$ & $28(16.5)$ & 4.027 & 0.134 \\
\hline & mixed & $3(50.0)$ & $3(50.0)$ & & & $8(100.0)$ & $0(0.0)$ & & \\
\hline \multirow[t]{2}{*}{ lymphatic/venous invasion } & - & $89(55.3)$ & $72(44.7)$ & 0.059 & 0.809 & $196(80.7)$ & $47(19.3)$ & 0.433 & 0.511 \\
\hline & + & 19 (57.6) & $14(42.4)$ & & & $39(84.8)$ & $7(15.2)$ & & \\
\hline
\end{tabular}




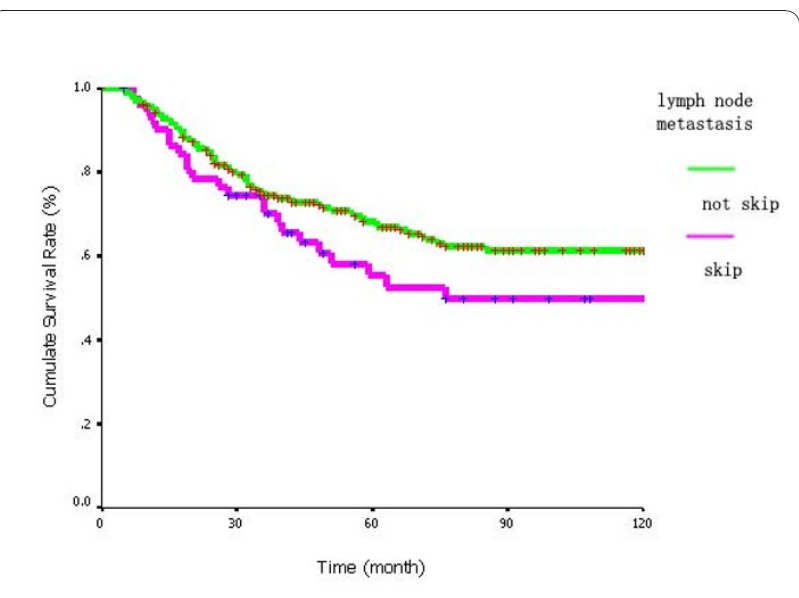

Figure 1 Survival curves of patients with and without skip metastasis. No significant difference was detected among patients with and without skip metastasis $\left(x^{2}=0.168, p=0.1951\right)$.

Second, only patients with pT1-2 stage were selected and who were all clinically staged as $\mathrm{cT}_{1 / 2} \mathrm{CN}_{0}$, as these patients usually considered eligible for sentinel node trial. It was reported that the sensitivity decreased and false-negative rate increased with an increase of $\mathrm{T}$ stage in SNB $[10,17]$. Only pT1-2 stage inclusion avoided the bias due to the lymphatic obstruction in advanced gastric carcinoma in SNB study. Third, patients with 1-3 positive nodes only restricted in the same compartment based on JCGC classification were chosen. Isozaki $\mathrm{H}$ et al. reported that two patients with sentinel nodes in no. $4 \mathrm{~d}$ also had another lymph node metastasis at the lesser curvature [17]. This phenomenon was also discovered by Osaka $\mathrm{H}$ et al. from micrometastasis level [23]. In their study, four patients with 2-5 blue-dyed nodes had micrometastasis in 2-3 nodes. Considering the number of $\mathrm{SN}$ per patient is 1-12 with an average of 3 and those mentioned above, it is more reasonable that $1-3$ positive nodes in the same compartment are considered as the initial lymphatic drainage sites (SNs).

In this study, we valuated the 1-3 positive nodes distribution and compared those with SLM. Most positive nodes occurred in N1 compartment, with frequency from $79.6 \%$ to $85.7 \%$ based on different tumor site. The other $14.3 \%$ to $20.4 \%$ patients metastasized in N2 compartment directly without N1 involved. The no. 7, 8a, 9 and $11 \mathrm{p}$ stations were the most common sites. Our results were consistent with other reports, in which lymph node metastasis was distributed beyond the perigastric area in $12.6 \%$ to $29.0 \%$ of gastric cancer patients [15,16,21,24-26]. When compared with SLM, indeed some differences existed in node distribution between them. In patients located in the lower third of stomach with 1-3 positive nodes, the frequency of no. 5 and no. 6 infiltrated was higher than that in SLM, and no. 6 was the most common metastatic site, no. 3 was the second, the order was reversed for SLM. Among the cancers of other site, the location and distribution of positive nodes in N1 and N2 (skip metastasis) was similar. This is a novel insight about SNs distribution in gastric cancer that never reported before.

To know the distribution of the SNs contributes to choose more suitable lymphadenectomy. In the present study, transverse metastasis was quite common, amounted to $41.2 \%$ and $50.8 \%$ in the lesser and greater curvature, respectively. The rate is a little higher than previous reports $[21,24]$. The patients with more than one positive node included in this study maybe the main reason. It was also frequent that two stations were involved simultaneously, most of which occurred in the neighboring or opposite stations in the same compartment. Furthermore, with increasing the depth of tumor invasion, a progressively augmented nodal involvement was showed, including the number of stations involved and the frequency of some stations especially in N2 compartment. 4 patients in the upper third of stomach with two stations involved in N2 compartment were all proved as ss (pT2b) pathologically. All of above indicate that single lymph node dissection is not recommended, and the en-bloc dissection of lymphatic basins from the cancer should be performed to avoid the occurrence of false negative SLN, in the context of SLN biopsy, as the existence of high frequency of transversal and 2 stations lymph node metastasis.

Achieving an R0 resection is a critical step in obtaining local-regional control, but limitting the extent of lymphadenectomy is apt to expose some patients to the possibility of incomplete dissection. Skip metastasis was found in $14.3 \%-20.4 \%$ patients with $1-3$ metastatic lymph nodes. When the influenced factors on skip metastasis were analyzed, none was found to be associated with it. This was also confirmed by Li C and Park SS [14,27]. Of note, the prognosis of patients with skip metastasis was as similar as that without skip metastasis after D2 or D3 lymphadenectomy. This means that in cases where metastasis first occurs in N2, the function of N2 in this situation is considered to be the same as N1. It suggests that we would achieve good surgical outcome if skip metastasis is found and dissected thoroughly. In order to obtain regional control, D2 lymphadenectomy is essential in patients with pT2 stage, as the higher occurrence of skip metastasis and higher frequency of some stations involved in N2 compartment in these patients.

\section{Conclusions}

In a word, although the results from this study don't present the distribution of $\mathrm{SN}$ in gastric carcinoma directly, they could provide some valuable information 
for the use of SN concept in the treatment. We can conclude that 1-3 positive nodes in the same compartment should be possible SNs, and most of which are restricted in N1 in pT1-2 gastric cancer. Transversal and 2 stations lymph node metastasis are common.

\section{List of Abbreviations}

SN: refers to sentinel node; SLM: refers to solitary lymph node metastasis; SNB: refers to sentinel node biopsy; sm: refers to submucosa based on depth of tumor invasion; mp: refers to muscularis propria based on depth of tumor invasion; ss: refers to subserosa based on depth of tumor invasion.

\section{Acknowledgements}

This study was supported the grants from the National 973 Program (No. G1998051203) and the National Natural Science Foundation of China (No. 30672050). We thank Dr. Jun Wang for elaboratively correcting the mistakes in grammar and spelling.

\section{Author details}

1 Department of Surgical Oncology, the First Hospital of China Medical University, Shenyang, 110001, PR China. ${ }^{2}$ Department of Oncological Sciences, Mount Sinai School of Medicine, New York, NY 10029, USA

\section{Authors' contributions}

HBJ and XHM conceived the study, analysed data, and drafted the manuscript and submitted the manuscript. WZN and SZ revised the manuscript critically for important intellectual content.

ZB conceived of the study and helped in drafting the manuscript. All authors read and approved the final manuscript.

\section{Competing interests}

The authors declare that they have no competing interests.

Received: 31 January 2010 Accepted: 17 January 2011

Published: 17 January 2011

\section{References}

1. Jemal A, Siegel R, Ward E, Hao Y, Xu J, Murray T, Thun MJ: Cancer statistics, 2008. CA Cancer J Clin 2008, 58:71-96.

2. Crew KD, Neugut Al: Epidemiology of gastric cancer. World J Gastroenterol 2006, 12:354-362.

3. Leung WK, Wu MS, Kakugawa Y, Kim JJ, Yeoh KG, Goh KL, Wu KC, Wu DC, Sollano J, Kachintorn U, Gotoda T, Lin JT, You WC, Ng EK, Sung JJ, Asia Pacific Working Group on Gastric Cancer: Screening for gastric cancer in Asia: current evidence and practice. Lancet Oncol 2008, 9(3):279-287.

4. Di Leo A, Marrelli D, Roviello F, Bernini M, Minicozzi A, Giacopuzzi S, Pedrazzani C, Baiocchi LG, de Manzoni G: Lymph node involvement in gastric cancer for different tumor sites and T stage: Italian Research Group for Gastric Cancer (IRGGC) experience. J Gastrointest Surg 2007, 11(9):1146-1153.

5. Park do J, Kong SH, Lee HJ, Kim WH, Yang HK, Lee KU, Choe KJ: Subclassification of pT2 gastric adenocarcinoma according to depth of invasion (pT2a vs pT2b) and lymph node status (pN). Surgery 2007, 141(6):757-563.

6. Oñate-Ocaña LF, Aiello-Crocifoglio $V$, Mondragón-Sánchez R, RuizMolina JM: Survival benefit of D2 lympadenectomy in patients with gastric adenocarcinoma. Ann Surg Oncol 2000, 7(3):210-217.

7. De Gara CJ, Hanson J, Hamilton S: A population-based study of tumornode relationship, resection margins, and surgeon volume on gastric cancer survival. Am J Surg 2003, 186(1):23-27.

8. Ryu KW, Lee JH, Kim HS, Kim YW, Choi IJ, Bae JM: Prediction of lymph nodes metastasis by sentinel node biopsy in gastric cancer. Eur J Surg Oncol 2003, 29(10):895-899.

9. Kitagawa Y, Kitano S, Kubota T, Kumai K, Otani Y, Saikawa Y, Yoshida M Kitajima M: Minimally invasive surgery for gastric cancer-toward a confluence of two major streams: A review. Gastric Cancer 2005, 8:103-110
10. Tajima Y, Yamazaki K, Masuda Y, Kato M, Yasuda D, Aoki T, Kato T, Murakami M, Miwa M, Kusano M: Sentinel node mapping guided by indocyanine green fluorescence imaging in gastric cancer. Ann Surg 2009, 249(1):58-62.

11. Kitagawa Y, Fujii H, Mukai M, Kubota T, Ando N, Watanabe M, Ohgami M, Otani Y, Ozawa S, Hasegawa H, Furukawa T, Kumai K, Ikeda T, Nakahara T, Kubo A, Kitajima M: The role of the sentinel lymph node in gastrointestinal cancer. Surg Clin North Am 2000, 80(6):1799-1809.

12. Arigami $T$, Natsugoe $S$, Uenosono $Y$, Mataki $Y$, Ehi $K$, Higashi $H$, Arima $H_{\text {, }}$ Yanagida S, Ishigami S, Hokita S, Aikou T: Evaluation of sentinel node concept in gastric cancer based on lymph node micrometastasis determined by reverse transcription-polymerase chain reaction. Ann Surg 2006, 243(3):341-347

13. Moenig SP, Luebke T, Baldus SE, Schroeder W, Bollschweiler E, Schneider PM, Hoelscher AH: Feasibility of sentinel node concept in gastric carcinoma: clinicopathological analysis of gastric cancer with solitary lymph node metastases. Anticancer Res 2005, 25(2B):1349-1352.

14. Li C, Kim S, Lai JF, Oh SJ, Hyung WJ, Choi WH, Choi SH, Noh SH: Solitary lymph node metastasis in gastric cancer. J Gastrointest Surg 2008, 12(3):550-554.

15. Kosaka T, Ueshige N, Sugaya J, Nakano Y, Akiyama T, Tomita F, Saito H, Kita I, Takashima S: Lymphatic routes of the stomach demonstrated by gastric carcinomas with solitary lymph node metastasis. Surg Today 1999, 29(8):695-700

16. Tsuburaya A, Noguchi Y, Yoshikawa T, Kobayashi O, Sairenji M, Motohashi H: Solitary lymph node metastasis of gastric cancer as a basis for sentinel lymph node biopsy. Hepatogastroenterology 2002, 49(47):1449-1452.

17. Isozaki H, Kimura T, Tanaka N, Satoh K, Matsumoto S, Ninomiya M, Ohsaki T, Mori M, Esophagus Gastrointestinal Surgical Treatment Study Group: An assessment of the feasibility of sentinel lymph node-guided surgery for gastric cancer. Gastric Cancer 2004, 7(3):149-153.

18. Rino Y, Takanashi Y, Hasuo K, Kawamoto M, Ashida A, Harada H, Inagaki D, Hatori S, Ohshima T, Yamada R, Imada T: The validity of sentinel lymph node biopsy using dye technique alone in patients with gastric cancer. Hepatogastroenterology 2007, 54(78):1882-1886.

19. Lee JH, Ryu KW, Nam BH, Kook MC, Cho SJ, Lee JY, Kim CG, Choi IJ, Park SR, Kim YW: Factors associated with detection failure and false-negative sentinel node biopsy findings in gastric cancer: results of prospective single center trials. J Surg Oncol 2009, 99(3):137-142.

20. Japanese Gastric Cancer Association: Japanese Classification of Gastric Carcinoma - 2nd English Edition. Gastric Cancer 1998, 1:10-24.

21. Ichikura T, Morita D, Uchida T, Okura E, Majima T, Ogawa T, Mochizuki H: Sentinel node concept in gastric carcinoma. World J Surg 2002, 26(3):318-322

22. Yasuda K, Inomata M, Fujii K, Shiraishi N, Adachi Y, Kitano S: Superficially spreading cancer of the stomach. Ann Surg Oncol 2002, 9(2):192-196.

23. Osaka H, Yashiro M, Sawada T, Katsuragi K, Hirakawa K: Is a lymph node detected by the dye-guided method a true sentinel node in gastric cancer? Clin Cancer Res 2004, 10(20):6912-6918.

24. Liu CG, Lu P, Lu Y, Jin F, Xu HM, Wang SB, Chen JQ: Distribution of solitary lymph nodes in primary gastric cancer: a retrospective study and clinical implications. World J Gastroenterol 2007, 13(35):4776-4780.

25. Tokunaga M, Ohyama S, Hiki N, Fukunaga T, Yamada K, Sano T, Yamaguchi T: Investigation of the Lymphatic Stream of the Stomach in Gastric Cancer with Solitary Lymph Node Metastasis. World J Surg 2009, 33:1235-1239.

26. Arai $K$, Iwasaki Y, Takahashi T: Clinicopathological analysis of early gastric cancer with solitary lymph node metastasis. Br J Surg 2002, 89:1435-1437.

27. Park SS, Ryu JS, Min BW, Kim WB, Kim SJ, Kim CS, Mok YJ: Impact of skip metastasis in gastric cancer. ANZ J Surg 2005, 75(8):645-649.

\section{Pre-publication history}

The pre-publication history for this paper can be accessed here: http://www.biomedcentral.com/1471-2407/11/18/prepub

doi:10.1186/1471-2407-11-18

Cite this article as: Huang et al: A novel insight of sentinel lymph node concept based on 1-3 positive nodes in patients with pT1-2 gastric cancer. BMC Cancer 2011 11:18. 